\title{
The Small-Scale Variation of Herb-Layer Community Structure in a Riparian Mixed Forest
}

\author{
Yulia Zhukova ${ }^{1, a^{*}}$, Nataliia Demchuk ${ }^{2, b}$, Nadiya Yorkina ${ }^{3, c}$, Yulia Dubinina ${ }^{4, d}$, \\ Dmytro Ganzha ${ }^{5, \mathrm{e}}$, Liudmila Bezugla ${ }^{2, \mathrm{f}}$, Tetiana Ilchenko ${ }^{2, \mathrm{~g}}$ \\ ${ }^{1}$ Department of the Zoology and Ecology, Oles Gonchar National University, Dnipro, Ukraine \\ ${ }^{2}$ Banking and Insurance Department, Dnipro State Agrarian and Economic University, \\ Dnipro, Ukraine
}

${ }^{3}$ Department of Environmental Safety and Rational Environmental Management, Bogdan Khmelnitsky Melitopol State Pedagogical University, Melitopol, Ukraine

${ }^{4}$ Department of Ecology and Information Technologies, Melitopol Institute of Ecology and Social Technologies of the Open International University of Human Development "Ukraine", Melitopol, Ukraine

5"Dnieper-Orilskiy" Nature Reserve, Obukhovka, Dniprovsk district, Dnipropetrovsk region, Ukraine

akaromeluka@gmail.com, bnatademchyk@gmail.com, cnadyayork777@gmail.com,

ddubinina4884@ya.ru, eganzha_kr_r@ukr.net, fmilabezugla@gmail.com, 9ilchetv26@gmail.com

Keywords: overstorey structure, soil properties, spatial pattern, phytoindication, scalogram, spatial eigenvector mapping.

\begin{abstract}
The role of spatial variables, soil properties and overstorey structure in spatial variation of the herb-layer community in a riparian mixed forest was shown. The research were conducted in the "Dnipro-Orils'kiy" Nature Reserve (Ukraine). The research polygon was laid in a forest in the floodplain of the River Protich, which is a left inflow of the River Dnipro. Plant abundance was quantified by measuring cover within experimental polygon. The experimental polygon consisted of 7 transects and each transect was made up of 15 test points. The distance between rows in the site was $3 \mathrm{~m}$. At the site we established a plot of $45 \times 21 \mathrm{~m}$, with 105 subplots of $3 \times 3 \mathrm{~m}$ organized in a regular grid. Vascular plant species lists were recorded for each $3 \times 3 \mathrm{~m}$ subplot along with visual estimates of species cover projection. The plant community was represented by 43 species, of which $18.6 \%$ were phanerophytes, $39.5 \%$ were hemikriptophytes, $9.3 \%$ were therophytes, $7.0 \%$ were geophytes. An overall test of random labelling revealed the total nonrandom distribution of the tree stems within the site. Constrained correspondence analysis (CCA) was applied as ordination approach. The forward selection procedure allowed us to select 6 soil variables, which explain $28.3 \%$ of the herb-layer community variability. The list of the important soil variables includes soil mechanical impedance (at the depth $0-5,30-35,75-80$, and 95-10 cm), soil moisture, and soil bulk density. The variation explained by pure spatial variables is equal to $11.0 \%$. The majority of the treedistance structured variation in plant community composition was broad-scaled. The significant relationship was found between the pure spatial component of the community variation and a lot of phytoindicator estimations of which the variability of damping and humidity were of the greatest importance. Trees stand was demonstrated to be a considerable factor structuring both the herb-layer community and spatial variation of the physical properties of soil.
\end{abstract}

\section{Introduction}

Floodplain forest ecosystems form the centers of biological diversity [1]. These ecosystems occupy a small part of the territory of the steppe zone of Ukraine, but there is a refuge of a large variety of soils, vegetation and animal communities [2]. The environmental processes occurring at landscape levels are directly reflected in the state of the floodplain ecosystems [3]. The small-scale variation of herb-layer community structure is affected by the soil properties, overstorey structural features and factors of the neutral nature. It should be noted that the nature of the influence of trees 
on herbaceous plants is much more complicated and involves the impact of trees on the habitat by modulating the availability of resources to other species [4]. The spatial component is presented in the soil properties variability and the overstorey effects on the understorey plant community. The nearest distance to the tree species can be considered as a very apparent measure of influence on the herbaceous plants. The arrangement of the different tree species can significantly complicate the structure of ecological space. The distance of the nearest tree is an easy and obvious measure of the impact of the overstorey both on the herbaceous layer and soil [5]. The herb-layer of forest ecosystems is influenced by the complex of factors, the source of which are soil conditions, the structure of a overstorey, interspecies interactions at the level of the herb-layer community and the factors of neutral nature. Neutral theory is based on the assumption that species of the community are 'neutral' in their ecological fitness [6]. An important feature is that almost all of these factors are spatially structured. The neutral processes may be modeled by means of the spatial factors [7]. The spatial structure has a certain scale hierarchy. The environmental variables explain mostly broad-scaled spatial patterns [8]. The factors of different nature are mainly manifested at different scale levels, which is especially important for assessing those that cannot be directly measured or is difficult to measure [9]. This is especially true for the neutral nature factors, which in a time dimension occupy a considerably wider range than the duration of conventional environmental observations. The soil physical properties form fine-scale patterns of an endogenous nature. Also fine-scale morphological soil structure may be appeared due to the trees influence. Morphological structure of soil on the fine-scale level is interpreted as the soil ecomorphes. The fine-scale structured soil patterns demonstrate ability to effect on the herb layer stratum [10]. Soil variables are able to explain both broad-scale and fine-scale spatial patterns [11].

The estimation of the influence of the spatial organization of an overstorey on the herb-layer is also a difficult task. The various components in the soil properties are highly correlated [12]. The impact of trees has a complex spatial organization, or is very changeable in time. Trees are capable of modifying properties of the soil in their neighborhood [13]. The latter circumstance is particularly related to the light regime. Sunlight penetration through the canopy determines directly the spatial pattern of the herb-layer community structure [14]. The amount of light that passes through the tree crown depends on many factors that vary significantly during the day, in seasons and throughout the year. The light variability mediated by the stand density is the important environmental regime which determines the interactions between organisms and their physical environments [15]. In this regard, the integrated indicators of the plant community response to tree stand effect has a certain advantage, as they reflect a regular pattern of the impact of trees on the environment [16].

The estimation of impact of different sources is complicated due to their mutual inrerralation. Tree species have a significant impact on humus characteristics, which significantly explain the distribution of forest understorey species [17]. This relationship can be functional or indirect. Trees are also a factor influencing variability of the soil conditions, and soil conditions affect the dynamics of growth and the tree state. General regimes, which are caused by relief or parent materials, effect both on trees and soils.

The aim of this study is to evaluate the role of spatial variables, soil properties and overstorey structure in spatial variation of the herb-layer community in a riparian mixed forest.

\section{Materials and Methods}

\section{Study area}

The research were conducted in the "Dnipro-Orils'kiy" Nature Reserve (Ukraine) (Fig. 1). The experimental polygon $\left(48^{\circ} 30^{\prime} 56^{\prime \prime} \mathrm{N}, 34^{\circ} 49^{\prime \prime} 21^{\prime \prime} \mathrm{E}\right)$ was located in a forest in the floodplain of the River Protich, which is a left inflow of the River Dnipro. The territory has a temperate-continental climate with an annual mean maximum decade temperature of $25.7^{\circ} \mathrm{C}$, and a minimum of $-10.0^{\circ} \mathrm{C}$, and with a mean annual precipitation of approximately $565 \mathrm{~mm} \mathrm{(20} \mathrm{year} \mathrm{average} \mathrm{according} \mathrm{to} \mathrm{data} \mathrm{of} \mathrm{the}$ Dnipro meteorological station). The study site comprises 0.945 ha of deciduous woodland bordered by an arena terrace above floodplain of the River Dnipro. Forests in the steppe zone of Ukraine have 
a very restricted distribution and usually have an island status which implies a considerable impact of the surrounding non-forest environment [5].

\section{Data collection}

The abundance of plant species was quantified by measuring cover within each subplot of the experimental polygon. The experimental polygon consisted of 7 transects and each transect was made up of 15 subplots with size $3 \times 3 \mathrm{~m}$ [5]. The adjacent subplots were in close proximity. The projective cover of plant species was recorded at ground level (hemikriptophytes, therophytes, and geophytes), the understorey (up to $2 \mathrm{~m}$ height, nanophanerophytes) and canopy (above $2 \mathrm{~m}$ height, phanerophytes). We were able to make species level identification for all subplots. Seedlings and saplings of woody species were later excluded from the analyses. Within the plot, all tree stems $\geq 20$ $\mathrm{cm}$ in diameter at breast height were measured and mapped. Dixon's segregation index was calculated for tree species to quantify their relative spatial mixing. The measure of segregation describes the tendency of one species to be associated with itself or with other species [18].

The investigated biotope may be identified as G1.22 Mixed oak-elm-ash woodland of great rivers according to the EUNIS classification or 91F0 Riparian mixed forests of Quercus robur, Ulmus laevis and Ulmus minor, Fraxinus excelsior or Fraxinus angustifolia, along the great rivers of the Atlantic and Middle-European provinces (Ulmenion minoris) according to the Council Directive 92/43/EEC [19]. In syntaxonomic aspect the vegetation can be identified as follows:

Class Alno glutinosae-Populetea albae P. Fukarek et Fabijanić 1968

Ordo Alno-Fraxinetalia excelsioris Passarge et G. Hofmann 1968

Alliance Alnion incanae Pawłowski, Sokołowski et Wallisch 1928

Ass. Ficario-Ulmetum minoris Knapp 1942 em. J.Matuszkiewicz 1976

Subass. Ficario-Ulmetum minoris franguletosum alni Onyshchenko 2009

Based on geobotanical descriptions, phytoindicative assessment of environmental factors according to Didukh [20] was made. Measurement of soil mechanical impedance was carried out in the field using a hand penetrometer Eijkelkamp, to a depth of $100 \mathrm{~cm}$ with an interval of $5 \mathrm{~cm}$. The average error of the measurement results of the device is $\pm 8 \%$. The measurements were made by a cone with a cross-sectional dimension of $2 \mathrm{~cm}^{2}$. Within each measurement point, the mechanical impedance of the soil was made in a single repeatability [21]. To measure the electrical conductivity of the soil in situ, a sensor HI 76305 was used (Hanna Instruments, Woonsocket, R. I.). The soil bulk density was estimated by Kachinskiy, soil moisture by weight method. The aggregate structure was evaluated by the dry sieving method according to Savinov [22]. The percentage content of such fractions is established: $<0.25,0.25-0.5,0.5-1,1-2,2-3,3-5,5-7,7-10,>10 \mathrm{~mm}$. 


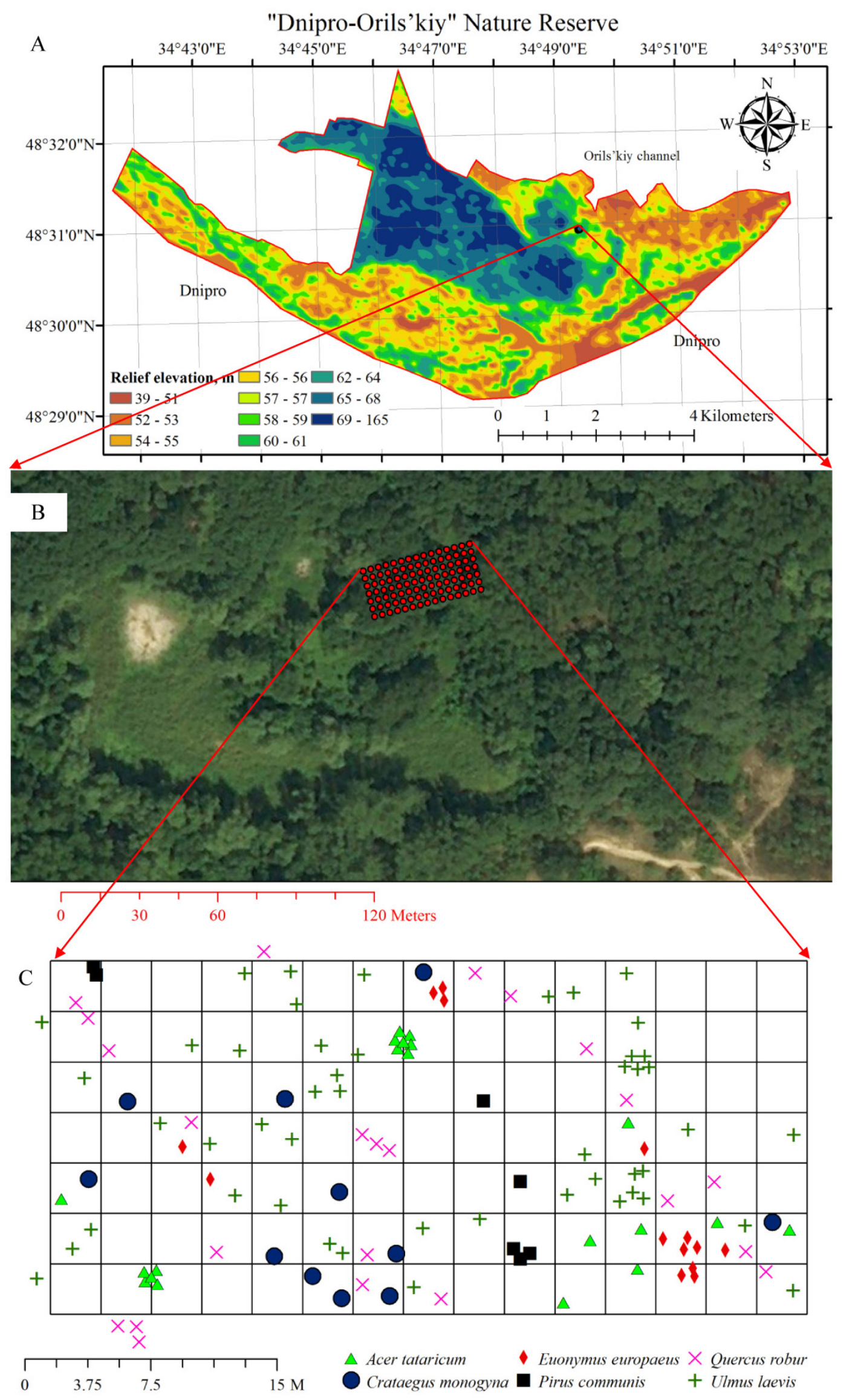

Figure 1. Placing of experimental polygon and the sampling points. A - the map of the "DniproOrils'kiy" Nature Reserve; B - the satellite image of the territory around the research polygon; $\mathrm{C}$ - scheme of the research polygon and three species individual locations 
Litter layer thickness was measured by ruler at 5 sampling points per sample subplot. The soil identification according to the WRB (IUSS Working Group WRB 2015) is Fluvic Calcic Gleysol (Loamic, Humic) [23].

\section{Data analyses}

As plant cover data tended to be left-skewed ( $J$-shaped), right skewed ( $L$-shaped) or U-shaped, the statistical assumptions of the plant cover data normality was rejected. Plant cover was assumed as being beta-distributed [24]:

$$
f_{X}(x)=\frac{1}{B(\alpha, \beta)} x^{\alpha-1}(1-x)^{\beta-1},
$$

where $f_{X}(x)$ - the probability density function, $\alpha, \beta>0$ - shape parameters, $B(\alpha, \beta)$ - beta function. The shape parameters of beta distribution were found on the basis of the experimental data by means of the betaCvMfit function of the R [25] package RobPer [26]. The estimation of the mean of plant cover projection was done as follows:

$$
P C_{\text {mean }}=100 \% \frac{\alpha}{\alpha+\beta},
$$

where $P C_{\text {mean }}$ - the mean of plant cover projection, $\%, \alpha, \beta$ - shape parameters of the beta distribution. The variance of the plant cover projection was done as follows:

$$
P C_{\text {var }}=\frac{\alpha \beta}{(\alpha+\beta)^{2}(\alpha+\beta+1)}
$$

where $P C_{v a r}$ - the variance of plant cover projection, $\alpha, \beta$ - shape parameters of the beta distribution. The nonparametric bootstrap confidence interval of the plant cover projection was estimated by means of the boot.ci function of the R package boot [27].

Constrained correspondence analysis (CCA) was applied to model of the variance in herb layer species composition [28]. Before the analyses, percentage cover of species was arcsine transformed. Soil mechanical impedance, soil electrical conductivity, litter layer thickness, moisture and soil bulk density were log transformed. The significance of CCA global model including all soil variables was first tested. A soil model based on the forward selection of soil variables was built with double stopping rule (alpha significance level and the $R_{a d j}^{2}$ calculated using all explanatory variables) [29]. Variables were retained only with a significant relationship to community composition $(p<0.05$, 9999 permutations). The models' marginal effect was computed, in which each selected soil variable was used separately as a predictor of community composition and the significance of all the models was tested and $R^{2}$ adj was extracted.

The geographic coordinates of sampling locations were used to generate a set of orthogonal eigenvector-based spatial variables (dbMEMs), each of them representing a pattern of particular scale within the extent of the sampling area [30]. The forward-selection procedure on partial RDAs with previously selected soil factors as covariables was applied to the subset of spatial variables. The significance of soil models with selected spatial variables as covariables was tested by the Monte Carlo permutation test (9999 permutations) [5].

The distance matrix from the nearest tree of each species was applied as a measure of the overstorey spatial structure. The distance matrix of sampling locations was provided the opportunity to generate eigenvector-based spatial variables (dbMEMs-tree based). The forward-selection procedure on partial CCAs with previously selected soil factors as covariables was applied to the subset of tree-structured spatial variables and the significance of environmental models with selected spatial variables as covariables was tested by the Monte Carlo permutation test (9999 permutations) [5].

In the next phase of the study, the dbMEMs were forward-selected directly on community data to explore patterns in community variation by variance partitioning between environmental and spatial influence. The significance of pure spatial and environmental fractions was tested by Monte Carlo permutation tests with 999. The scalogram approach was applied to inspect in detail the spatial scaling of community variation [31]. To do this, the two sets of CCA analyses were carried out with each of the dbMEM variables as a predictor. As a response variable, the first set of CCA analyses used raw (arcsine transformed) species data, while the second set used residuals of the environmental 
model in which forward-selected environmental variables acted as predictors [8]. From each CCA we extracted $R_{a d j}^{2}$ for individual dbMEMs and plotted them into juxtaposed barplots [32]. Phytoindication estimation of the ecological factors [20] was used to find an ecological interpretation of spatial structures in community composition not explained by environmental variables [33].

The environmental factors were fitted onto a CCA-ordination by enfit function from the vegan library [34]. The constrained ordination approaches (correspondence or redundancy analysis) allowed assessment of the effects of the soil moisture as an explanatory variable on the invertebrate community with temporal, spatial, environmental factors and soil type as condition variables. The detrended correspondence analysis (DCA) was used to discriminate whether species responses are primarily monotonic or primarily unimodal. To do this, the length of the first major gradient of variation in community data was estimated [35]. If gradient length is more than 2 standard deviation, then constrained correspondence analysis (CCA) must be selected as ordination approach. Otherwise constrained redundancy analysis (RDA) is most suitable. All statistical analyses were conducted in R (v. 3.5.0., R Foundation for Statistical Computing, Vienna, AT), using the following packages: vegan (v. 2.5-2, https://CRAN.R-project.org/package=vegan) for the multivariate analysis and for the computation of global and partial Moran's I. [34], adespatial (v. 0.3-2. https://CRAN.Rproject.org/package=adespatial) for the forward selection and for the generation of spatial filters [36], dixon for testing the spatial segregation and association based on contingency table analysis of nearest neighbour count [37], spatstat for density estimation of the tree stems' spatial distribution [38].

\section{Results}

The plant community was represented by 43 species, of which $18.6 \%$ were phanerophytes, $39.5 \%$ were hemikriptophytes, $9.3 \%$ were therophytes, $7.0 \%$ were geophytes (Table 1). The Quercus robur L. and Ulmus laevis Pall. were characterized by the largest projection cover (23.5 and 13.3\% respectively) among phanerophytes. The Acer tataricum L., Cornus sanguinea L., and Crataegus Monogyna Jacq. had the largest projection cover among the nanophanerophytes $(5.5,2.2$, and 2.2\% respectively). The Urtica dioica L. (6.7\%) and Geranium robertianum L. (3.1\%) had the largest projection cover among hemikriptophytes. The Galium aparine L. (6.4\%) and Anthriscus cerefolium (L.) Hoffm (10.4\%) had the largest projection cover among therophytes (6.4 and $10.4 \%$ respectively). The Convallaria majalis L. had the largest projection cover among geophytes $(10.5 \%)$.

The forest overstorey included Quercus robur L. (18.7\% of total tree stems), Ulmus laevis Pall (39.0 \%), and Pyrus communis L. (5.7\%). The forest understory included Acer tataricum L. (16.3\% of total tree stems), Crataegus monogyna Jacq. (8.9\%), and Euonymus europaeus L. (11.4\%). The distance from the sampling locations to Quercus robur stems was $3.8 \pm 0.21 \mathrm{~m}$ (maximum $-11.4 \mathrm{~m}$ ), to Ulmus laevis stems was $2.7 \pm 0.16 \mathrm{~m}$ (maximum $-8.8 \mathrm{~m}$ ), to Pyrus communis stems was $9.3 \pm 0.56$ $\mathrm{m}$ (maximum - $19.3 \mathrm{~m}$ ), to Acer tataricum stems was $5.8 \pm 0.32 \mathrm{~m}$ (maximum - $13.4 \mathrm{~m}$ ), to Crataegus monogyna stems was $5.8 \pm 0.32 \mathrm{~m}$ (maximum - $13.4 \mathrm{~m}$ ), and to Euonymus europaeus was $6.4 \pm 0.31 \mathrm{~m}$ (maximum $-14.2 \mathrm{~m}$ ). 
Table 1. Plant community composition and descriptive statistic of the plan species projective cover

\begin{tabular}{|c|c|c|c|c|c|c|}
\hline \multirow{2}{*}{ Raunkiær plant life-form and species } & \multicolumn{2}{|c|}{$\begin{array}{c}\text { Beta-distribution } \\
\text { shape parameters }\end{array}$} & \multirow{2}{*}{$\begin{array}{l}\text { Projective } \\
\text { cover, \% }\end{array}$} & \multirow{2}{*}{ Variance } & \multicolumn{2}{|c|}{ Confidence interval } \\
\hline & Alpha & Beta & & & $2.5 \%$ & $97.5 \%$ \\
\hline \multicolumn{7}{|c|}{ Phanerophytes } \\
\hline Acer negundo L. & 0.25 & 31.98 & 0.79 & 0.02 & 0.52 & 1.12 \\
\hline Fraxinus excelsior $\mathrm{L}$. & 0.01 & 98.98 & 0.01 & 0.0001 & 0.00 & 0.03 \\
\hline Populus nigra $\mathrm{L}$. & 0.05 & 10.25 & 0.53 & 0.05 & 0.22 & 1.11 \\
\hline Pyrus communis $\mathrm{L}$. & 0.16 & 2.29 & 6.43 & 1.74 & 4.29 & 9.29 \\
\hline Quercus robur $\mathrm{L}$. & 1.68 & 5.49 & 23.48 & 2.20 & 20.57 & 26.24 \\
\hline Salix alba $\mathrm{L}$. & 0.03 & 13.93 & 0.19 & 0.01 & 0.05 & 0.55 \\
\hline Ulmus laevis Pall. & 1.85 & 12.05 & 13.31 & 0.77 & 11.69 & 15.04 \\
\hline Ulmus minor Mill. & 0.009 & 98.98 & 0.010 & 0.0001 & 0.00 & 0.029 \\
\hline \multicolumn{7}{|c|}{ Nanophanerophytes } \\
\hline Acer tataricum $\mathrm{L}$. & 0.61 & 10.54 & 5.49 & 0.43 & 4.34 & 6.84 \\
\hline Amorpha fruticosa $\mathrm{L}$. & 0.33 & 22.15 & 1.47 & 0.06 & 1.05 & 1.98 \\
\hline Berberis vulgaris $\mathrm{L}$. & 0.01 & 98.98 & 0.010 & 0.0001 & 0.00 & 0.029 \\
\hline Cornus sanguinea $\mathrm{L}$. & 0.21 & 9.44 & 2.21 & 0.20 & 1.50 & 3.29 \\
\hline Crataegus monogyna Jacq. & 0.30 & 13.31 & 2.22 & 0.15 & 1.56 & 3.04 \\
\hline Euоnутиs europaeus L. & 0.08 & 20.28 & 0.38 & 0.02 & 0.14 & 0.62 \\
\hline Frangula alnus Mill. & 0.04 & 16.73 & 0.26 & 0.01 & 0.10 & 0.62 \\
\hline Parthenocissus quinquefolia (L.) Planch. & 0.009 & 32.31 & 0.029 & 0.001 & 0.00 & 0.086 \\
\hline Rhamnus cathartica L. & 0.019 & 99.93 & 0.019 & 0.0002 & 0.00 & 0.048 \\
\hline Rubus caesius $\mathrm{L}$. & 0.13 & 28.07 & 0.46 & 0.02 & 0.25 & 0.75 \\
\hline Sambucus nigra $\mathrm{L}$. & 0.29 & 16.85 & 1.68 & 0.09 & 1.17 & 2.36 \\
\hline \multicolumn{7}{|c|}{ Hemikriptophytes } \\
\hline Alliaria petiolata (M.Bieb.) Cavara et Grande & 0.35 & 16.71 & 2.05 & 0.11 & 1.49 & 2.77 \\
\hline Anthriscus sylvestris (L.) Hoffm. & 0.07 & 22.40 & 0.32 & 0.01 & 0.14 & 0.62 \\
\hline Arctium lappa $\mathrm{L}$. & 0.19 & 18.11 & 1.06 & 0.05 & 0.70 & 1.63 \\
\hline Brachypodium sylvaticum (Huds.) P.Beauv. & 0.11 & 56.72 & 0.19 & 0.003 & 0.10 & 0.32 \\
\hline Calystegia sepium (L.) R.Br. & 0.08 & 41.73 & 0.19 & 0.004 & 0.09 & 0.35 \\
\hline Carex pilosa Scop. & 0.15 & 32.11 & 0.48 & 0.01 & 0.29 & 0.75 \\
\hline Chelidonium majus L. & 0.60 & 26.21 & 2.25 & 0.08 & 1.79 & 2.85 \\
\hline Cynoglossum officinale L. & 0.009 & 32.31 & 0.029 & 0.001 & 0.00 & 0.086 \\
\hline Geranium robertianum L. & 0.36 & 11.20 & 3.13 & 0.24 & 2.30 & 4.19 \\
\hline Geum urbanum L. & 0.45 & 37.73 & 1.19 & 0.03 & 0.90 & 1.56 \\
\hline Glechoma hederacea L. & 0.37 & 18.98 & 1.90 & 0.09 & 1.37 & 2.52 \\
\hline Leonurus cardiaca L. & 0.019 & 99.93 & 0.019 & 0.0002 & 0.00 & 0.048 \\
\hline Poa nemoralis L. & 0.09 & 107.15 & 0.09 & 0.001 & 0.04 & 0.14 \\
\hline Scrophularia nodosa $\mathrm{L}$. & 0.30 & 25.05 & 1.17 & 0.04 & 0.81 & 1.61 \\
\hline Silene baccifera (L.) Roth & 0.38 & 17.82 & 2.11 & 0.11 & 1.56 & 2.83 \\
\hline Symphytum officinale L. & 0.024 & 36.36 & 0.067 & 0.002 & 0.010 & 0.181 \\
\hline Urtica dioica $\mathrm{L}$. & 0.65 & 9.11 & 6.68 & 0.58 & 5.40 & 8.30 \\
\hline \multicolumn{7}{|c|}{ Therophytes } \\
\hline Anthriscus cerefolium (L.) Hoffm. & 0.93 & 8.03 & 10.35 & 0.93 & 8.64 & 12.33 \\
\hline Erodium cicutarium (L.) L'Hér. & 0.019 & 99.93 & 0.019 & 0.0002 & 0.00 & 0.048 \\
\hline Galium aparine $\mathrm{L}$. & 2.85 & 21.92 & 11.52 & 0.40 & 10.37 & 12.74 \\
\hline Stellaria media $(\mathrm{L}$.$) Vill$ & 0.74 & 10.78 & 6.42 & 0.48 & 5.19 & 7.80 \\
\hline \multicolumn{7}{|c|}{ Geophytes } \\
\hline Convallaria majalis $\mathrm{L}$. & 0.24 & 2.09 & 10.48 & 2.81 & 7.62 & 14.05 \\
\hline Humulus lupulus $\mathrm{L}$. & 0.046 & 40.42 & 0.114 & 0.003 & 0.038 & 0.248 \\
\hline Lamium album $\mathrm{L}$. & 0.019 & 99.93 & 0.019 & 0.0002 & 0.00 & 0.048 \\
\hline
\end{tabular}


An overall test of random labelling revealed the total nonrandom distribution of the tree stems within the site (overall test of random labelling 146.6, $p$-value of the overall test from the asymptotic $c h i$-square distribution with the appropriate degrees of freedom is $<0.01$ ) (Table 2).

Table 2. The nearest neighbour contingency table and Dixon's spatial segregation test for tree species

\begin{tabular}{|c|c|c|c|c|c|c|c|}
\hline \multicolumn{2}{|c|}{ Species } & A. tataricum & C. monogyna & E. europaeus & P. communis & Q. robur & U. laevis \\
\hline \multirow{4}{*}{ A. tataricum } & Obs.Count & 12 & 2 & 2 & 1 & 1 & 2 \\
\hline & Exp. Count & 3.11 & 1.8 & 2.3 & 1.15 & 3.77 & 7.87 \\
\hline & $\mathrm{S}$ & 0.91 & 0.05 & -0.07 & -0.06 & -0.64 & -0.77 \\
\hline & $p$-value & $<0.01$ & 0.70 & 0.76 & 0.70 & 0.09 & $<0.01$ \\
\hline \multirow{4}{*}{ C. monogyna } & Obs.Count & 2 & 1 & 1 & 0 & 2 & 5 \\
\hline & Exp. Count & 1.8 & 0.9 & 1.26 & 0.63 & 2.07 & 4.33 \\
\hline & $\mathrm{S}$ & 0.05 & 0.05 & -0.11 & $-\operatorname{Inf}$ & -0.02 & 0.11 \\
\hline & $p$-value & 0.70 & 0.64 & 0.68 & 0.32 & 0.74 & 0.55 \\
\hline \multirow{4}{*}{$\begin{array}{c}E . \\
\text { europaeus }\end{array}$} & Obs.Count & 0 & 0 & 10 & 0 & 2 & 2 \\
\hline & Exp. Count & 2.3 & 1.26 & 1.49 & 0.8 & 2.64 & 5.51 \\
\hline & S & $-\operatorname{Inf}$ & $-\operatorname{Inf}$ & 1.32 & $-\operatorname{Inf}$ & -0.14 & -0.59 \\
\hline & $p$-value & 0.06 & 0.20 & $<0.01$ & 0.32 & 0.54 & 0.07 \\
\hline \multirow{4}{*}{ P. communis } & Obs.Count & 0 & 0 & 0 & 6 & 0 & 1 \\
\hline & Exp. Count & 1.15 & 0.63 & 0.8 & 0.34 & 1.32 & 2.75 \\
\hline & $\mathrm{S}$ & $-\operatorname{Inf}$ & $-\operatorname{Inf}$ & $-\operatorname{Inf}$ & 2.06 & $-\operatorname{Inf}$ & -0.59 \\
\hline & $p$-value & 0.19 & 0.33 & 0.33 & $<0.01$ & 0.20 & 0.14 \\
\hline \multirow{4}{*}{ Q. robur } & Obs.Count & 2 & 2 & 3 & 0 & 9 & 7 \\
\hline & Exp. Count & 3.77 & 2.07 & 2.64 & 1.32 & 4.15 & 9.05 \\
\hline & $\mathrm{S}$ & -0.31 & -0.02 & 0.06 & $-\operatorname{Inf}$ & 0.47 & -0.17 \\
\hline & $p$-value & 0.28 & 0.75 & 0.52 & 0.23 & 0.04 & 0.41 \\
\hline \multirow{4}{*}{ U. laevis } & Obs.Count & 0 & 4 & 3 & 1 & 6 & 34 \\
\hline & Exp. Count & 7.87 & 4.33 & 5.51 & 2.75 & 9.05 & 18.49 \\
\hline & $\mathrm{S}$ & $-\operatorname{Inf}$ & -0.04 & -0.29 & -0.46 & -0.21 & 0.59 \\
\hline & $p$-value & $<0.01$ & 0.82 & 0.27 & 0.21 & 0.20 & $<0.01$ \\
\hline
\end{tabular}

Note: Obs. count - observed nearest neighbor count; Exp. Count - expected nearest neighbor counts; $\mathrm{S}$ - segregation measure (values of $\mathrm{S}$ larger than 0 indicate that species is segregated; the larger the value of $\mathrm{S}$, the more extreme the segregation; values of $\mathrm{S}$ less than 0 indicate that species is found as neighbor of itself less than expected under random labelling. Values of $\mathrm{S}$ close to 0 are consistent with random labelling of the neighbors of species); $p$-value - based on the asymptotic normal distribution of the $\mathrm{Z}$ statistic

The species-specific test of random labelling showed the nonrandom segregated distribution of the Acer tataricum (segregation measure 11.1, $p<0.01$ ), Pyrus communis (segregation measure $\mathrm{S}=$ $2.1, p<0.01)$, Quercus robur $(\mathrm{S}=0.5, p=0.04)$, and Ulmus laevis $(\mathrm{S}=0.6, p<0.01)$. Crataegus monogyna and Euonymus europaeus were distributed randomly. The nearest neighbor of a Acer tataricum is less likely to be Ulmus laevis $(\mathrm{S}=-0.77, p<0.01)$. There was no direct spatial connection between Acer tataricum and other trees. The Crataegus monogyna, Pyrus communis, Quercus robur and Euonymus europaeus were no segregated with all other species. The nearest neighbor of a Ulmus laevis is less likely to be Acer tataricum ( $\mathrm{S}=\mathrm{Inf}, p<0.01$ ).

Soil mechanical impedance in the surface layer $0-5 \mathrm{~cm}$ was $0.72 \pm 0.01 \mathrm{MPa}$ (Fig. 2). By the depth of 35-40 cm, the changes of soil mechanical impedance were insignificant, while the local maximum of this soil property was observed at a depth of $15-20 \mathrm{~cm}$. After a depth of $40-45 \mathrm{~cm}$ there was a rapid growth of the soil mechanical impedance with depth resulting in the soil mechanical 
impedance at the depth of $95-100 \mathrm{~cm}$ reached value of $3.69 \pm 0.09 \mathrm{MPa}$. This indicates that the soil mechanical impedance within the investigated polygon can serve as a significant limiting factor that influences the structure of the herbaceous vegetation.

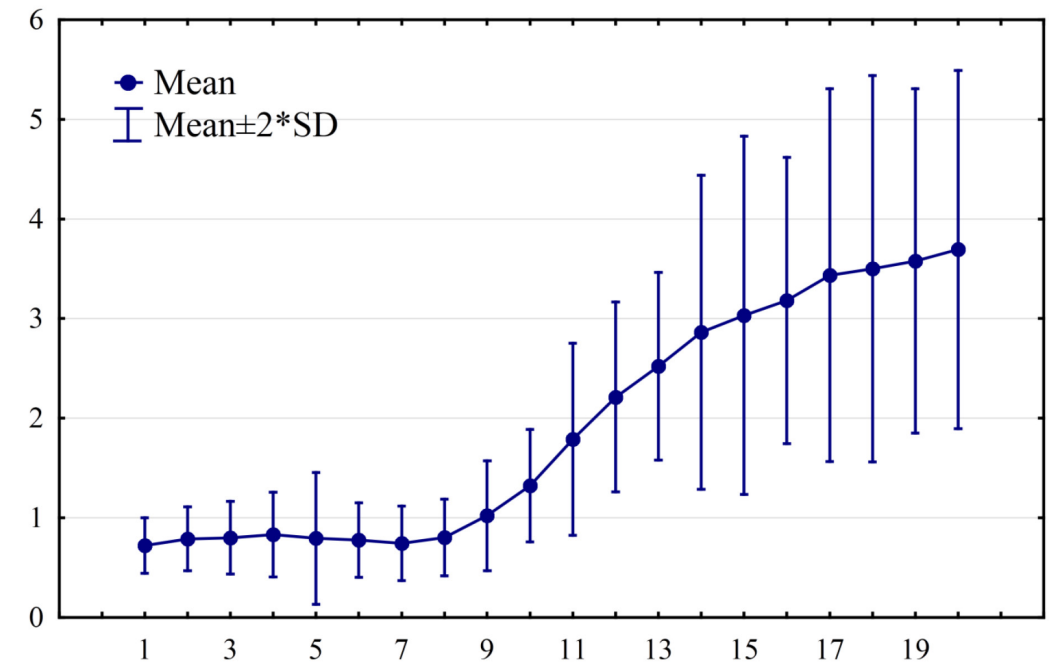

Figure 2. Soil mechanical impedance profile distribution. $X$ - axis is the soil layer depth: $1-0-5 \mathrm{~cm}$, ... $20-95-100 \mathrm{~cm}$; Y-axis is the soil mechanical impedance, MPa

Soil electrical conductivity of the soil surface layer was $0.49 \pm 0.06 \mathrm{dSm} / \mathrm{m}$ (Fig. 3). In $6.6 \%$ of cases the soil electrical conductivity value was higher than $2 \mathrm{dSm} / \mathrm{m}$. This value is a marker for a critical level of the soluble salt content in soil, which is able to limit plant growth [39].
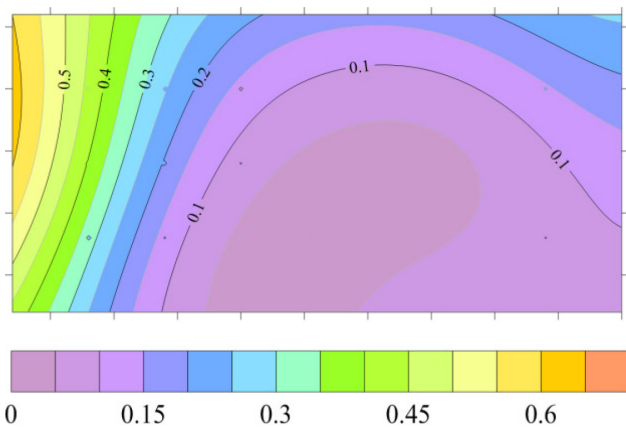

EC, $\mathrm{dSm} / \mathrm{m}$ (log-transformed)
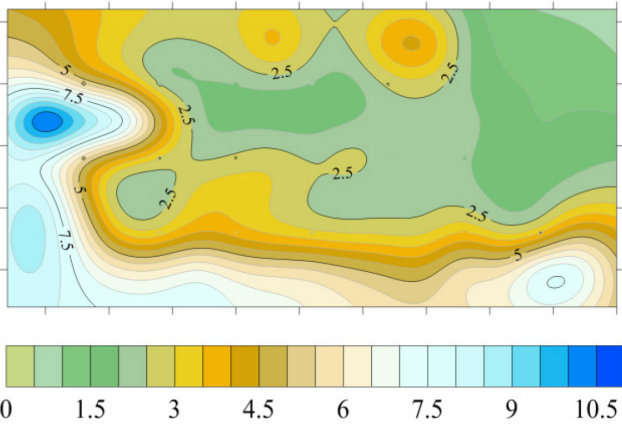

Soil water content, \%
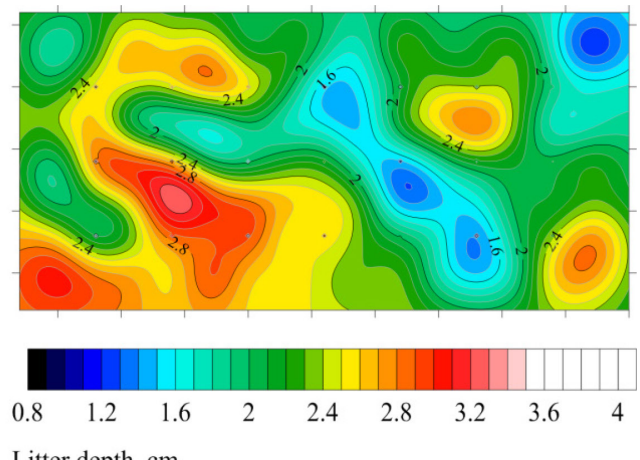

Litter depth, cm
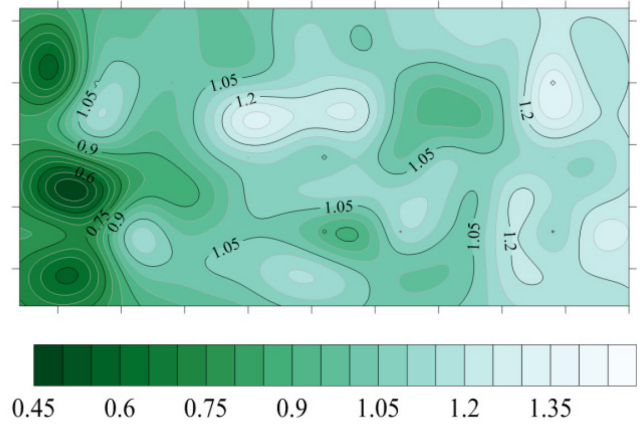

Bulk density, $\mathrm{g} / \mathrm{cm}^{3}$

Figure 3. Spatial variation of the soil variables within the experimental polygon

The forest litter depth varied from 0 to $4 \mathrm{~cm}$ with an average value of $2.23 \pm 0.07 \mathrm{~cm}$. The moisture content in the soil surface layer at the time of the study was $3.58 \pm 0.24 \%$. The bulk density of soil surface layer varied widely (from 0.33 to $1.48 \mathrm{~g} / \mathrm{cm}^{3}$ ). The macroaggregates larger than $10 \mathrm{~mm}$, the proportion of which was $23.46 \pm 0.98 \%$ (Fig. 4), had the greatest role in the soil aggregate structure. The gradient length of the first major gradient of variation in community data estimated due to DCA was more than 2 standard deviation (2.59), then constrained correspondence analysis 
(CCA) was applied as ordination approach. The model of the partial CCA of the plant community data including all soil variables as covariables was significant $\left(R_{a d j}^{2}=0.39, F=3.03, p<0.001\right)$. The forward selection procedure allowed us to select 6 soil variables, which explain $28.3 \%$ of the community variability $(F=7.84, p<0.001)$. The list of the important soil variables includes soil mechanical impedance (at the depth $0-5,30-35,75-80$, and $95-10 \mathrm{~cm}$ ), soil moisture, and soil bulk density.
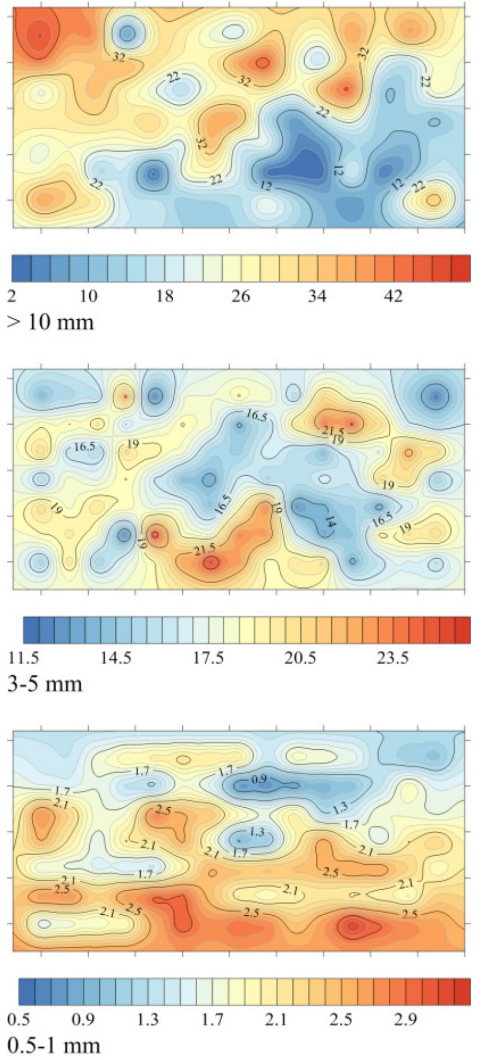
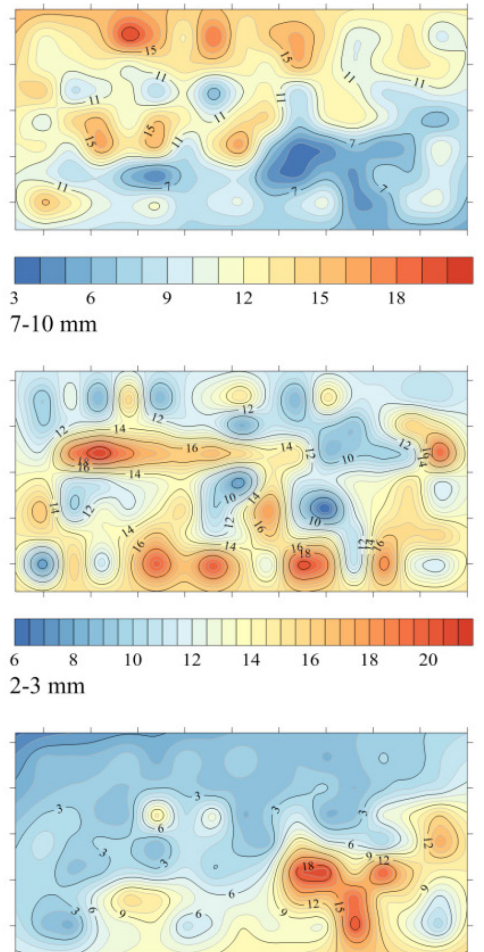

0.25-0.5 mm
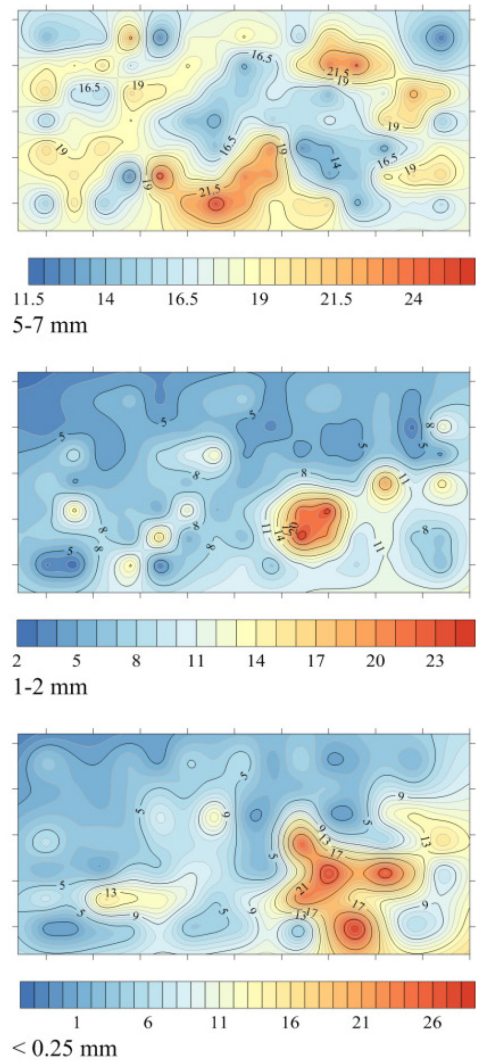

Figure 4. Spatial variation of the aggregate fractions

There are 48 dbMEMs-spatial variables with soil variables as covariables, which together explain $66.2 \%$ of the plant community variability. The forward selection procedure allowed us to select 18 variables, which explain $65.8 \%$ of the variability of the community $(F=6.81, p<0.001)$. The model of CCA including all dbMEMs-tree distance variables with soil variables as covariates was significant $\left(R_{a d j}^{2}=0.25, F=2.15, p<0.001\right)$. The forward selection procedure allowed us to select 2 variable (Fig. 5), which explains $14.3 \%$ of the variability of the plant community $(F=15.76$, $p<0.001)$.

The model of the partial CCA of the plant community data including all phytoindicator variables as covariables was significant $\left(R_{a d j}^{2}=0.30, F=4.65, p<0.001\right)$. The forward selection procedure allowed us to select 3 phytoindicator variables, which explain $28.4 \%$ of the community variability $(F=14.7, p<0.001)$. The list of the important phytoindicator variables includes the soil water regime $(H d)$, the soil aeration $(A e)$, and the light $(\mathrm{Lc})$.

The unexplained variation accounts for $65.1 \%$ (Fig. 6). The variation explained solely by soil variables is equal to $1.6 \%$, while the variation explained both by spatial and soil variables is $6.2 \%$. The soil, spatial and tree distance variables are able to explain $6.1 \%$ of the community variation. The variation explained by pure spatial variables is equal to $11.0 \%$. The role of the other sources of the variation is considerably low. 

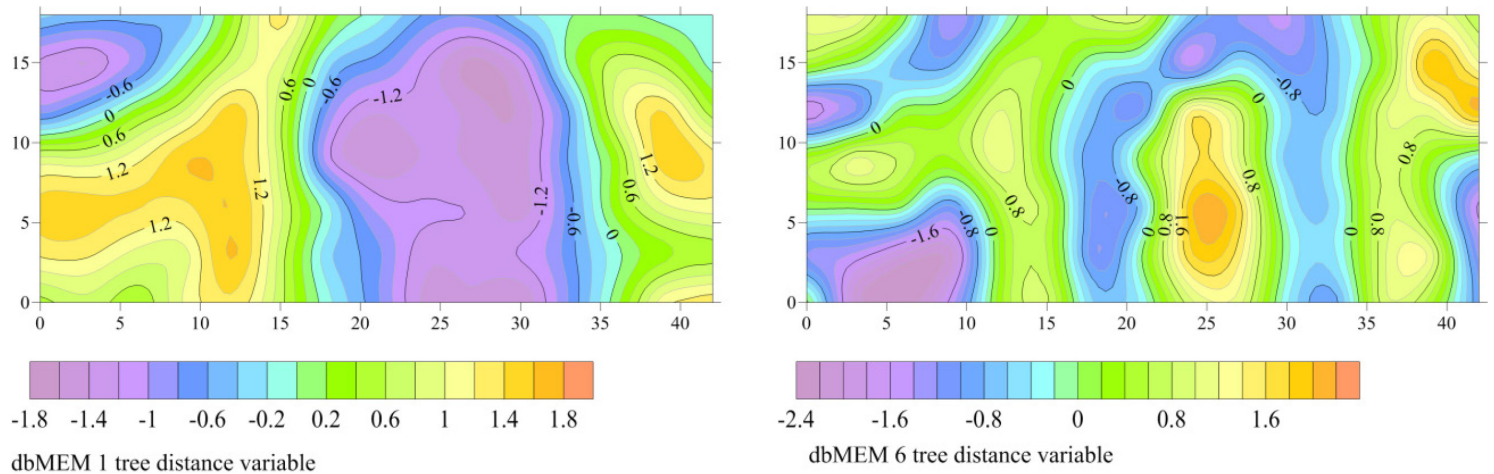

Figure 5. Spatial variation of the dbMEMs-tree distance variables within the experimental polygon

The majority of the tree-distance structured variation in plant community composition was broad-scaled (captured by dbMEMs-tree variables with lowest numbers) (Fig. 7). The soil, phytoindicator, and spatial effects were able to account for mainly broad- and mesoscale tree-distance structured variation. The pure tree induced spatial effect on the plant community was found to be statistically significant and embraced the broad- and partly mesoscale diapason of the community variation.
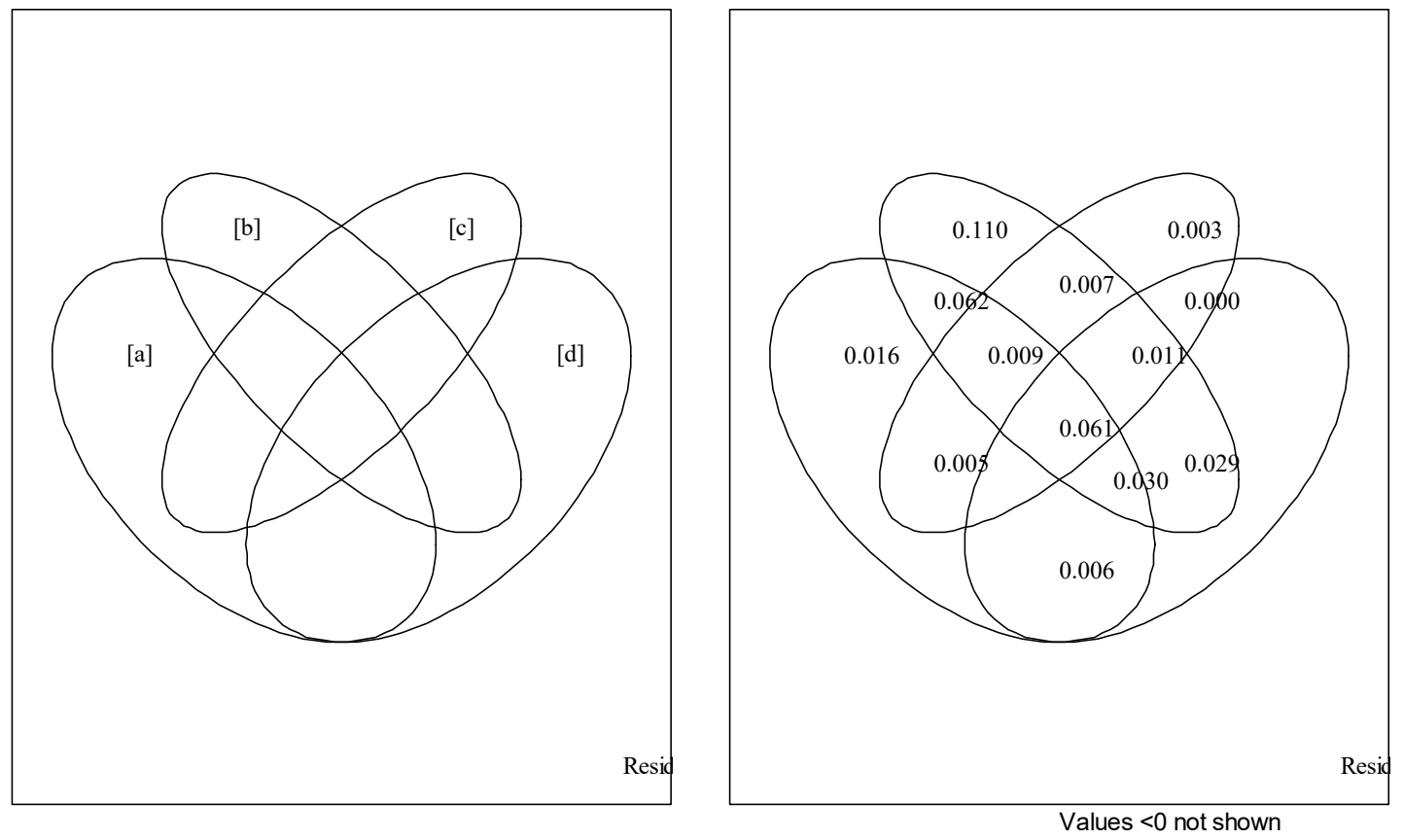

Figure 6. Variance partitioning between spatial, soil, phytoindicator and tree distance explanatory variables.

Notes: [a] - variation explained solely by soil variables; [b] - variation captured by spatial (dbMEM) variables corresponds to pure space (residual spatial component); [c] - variation captured by the distances from tree stems; [d] - explained solely by phytoinducator variables. The intersection of the ellipses corresponds to the variations explained by the respective sources together. All the variance fractions shown are significant $(p<0.001)$.

The spatial scalograms was a left-skewed asymmetric (Fig. 8). DbMEM-tree variables are able to increase the explanation of the plant community variation by the spatial variables. The soil and phytoindicator effects were able to account for spatially structured variation. The pure spatial effect on the plant community was found to be statistically significant and embraced the broad- and mesoscale diapason of the community variation. 

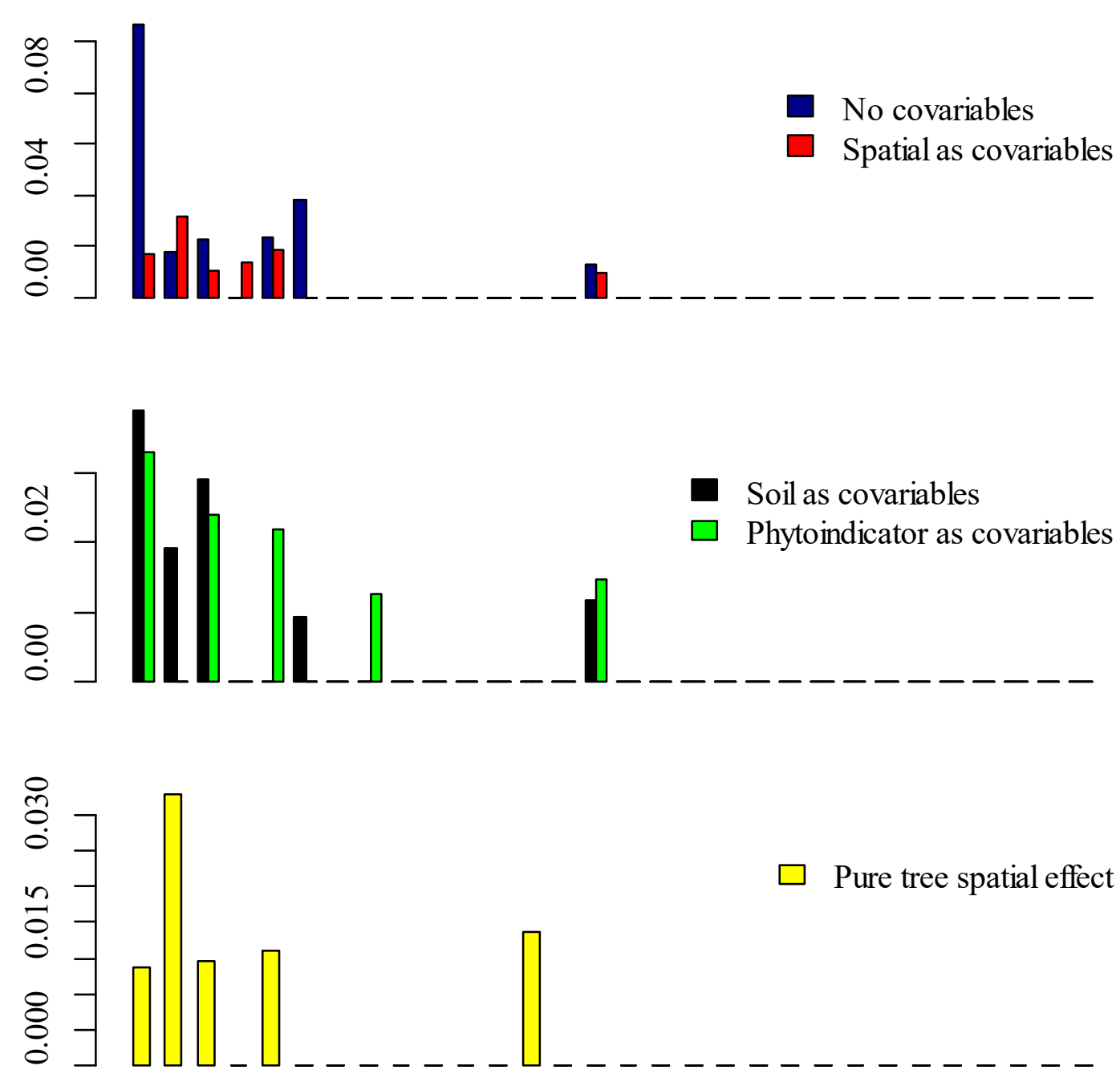

$\begin{array}{lllllllllllllll}1 & 3 & 5 & 7 & 9 & 11 & 13 & 15 & 17 & 19 & 21 & 23 & 25 & 27 & 29\end{array}$

Figure 7. Scalograms illustrating the scaling of tree structured variation in plant community data (No variables as covariables, blue bars) and residuals of the spatial models (red bars), soil models (black bars), plant models (green bars) and pure tree effect (yellow bars). The value of $R^{2}$ adj is the variation explained by individual dbMEM-tree variables. The dbMEMs are ordered decreasingly according to the scale of spatial patterns they represent ( $x$-axis is the number of dbMEM; dbMEM 1 represents the broadest scale, dbMEM 30 the finest scale).

The variation in plant community structure may be explained by the soil mechanical impedance at depth $0-5,30-35,35-40,45-50$, and $95-100 \mathrm{~cm}$, soil bulk density, moisture content, and portion of the aggregate fractions of $2-3 \mathrm{~mm}$ (Table 3 ). The spatial effect accounted for variation explained by soil mechanical impedance at depth $35-40,45-50$, and $95-100 \mathrm{~cm}$, soil moisture, and aggregate fractions. There was no phytoindicator partial effect on the soil mechanical impedance explanation ability and taking into account the phytoindicator effect led to increase the explanation ability of the edaphic parameters. The explanation ability of the soil bulk density and aggregate fractions considerably decreased after taking into account of the tree partial effect.

The significant relationship was found between soil induced community structure and phytoindication values of the soil water regime, variability of damping, total salt regime, and continentality of climate (Table 4). The significant relationship was found between the pure spatial component of the community variation and a lot of phytoindicator estimations of which the variability of damping and humidity were of the greatest importance. There was no a significant tree distance effect on the phytoindicator estimations. 

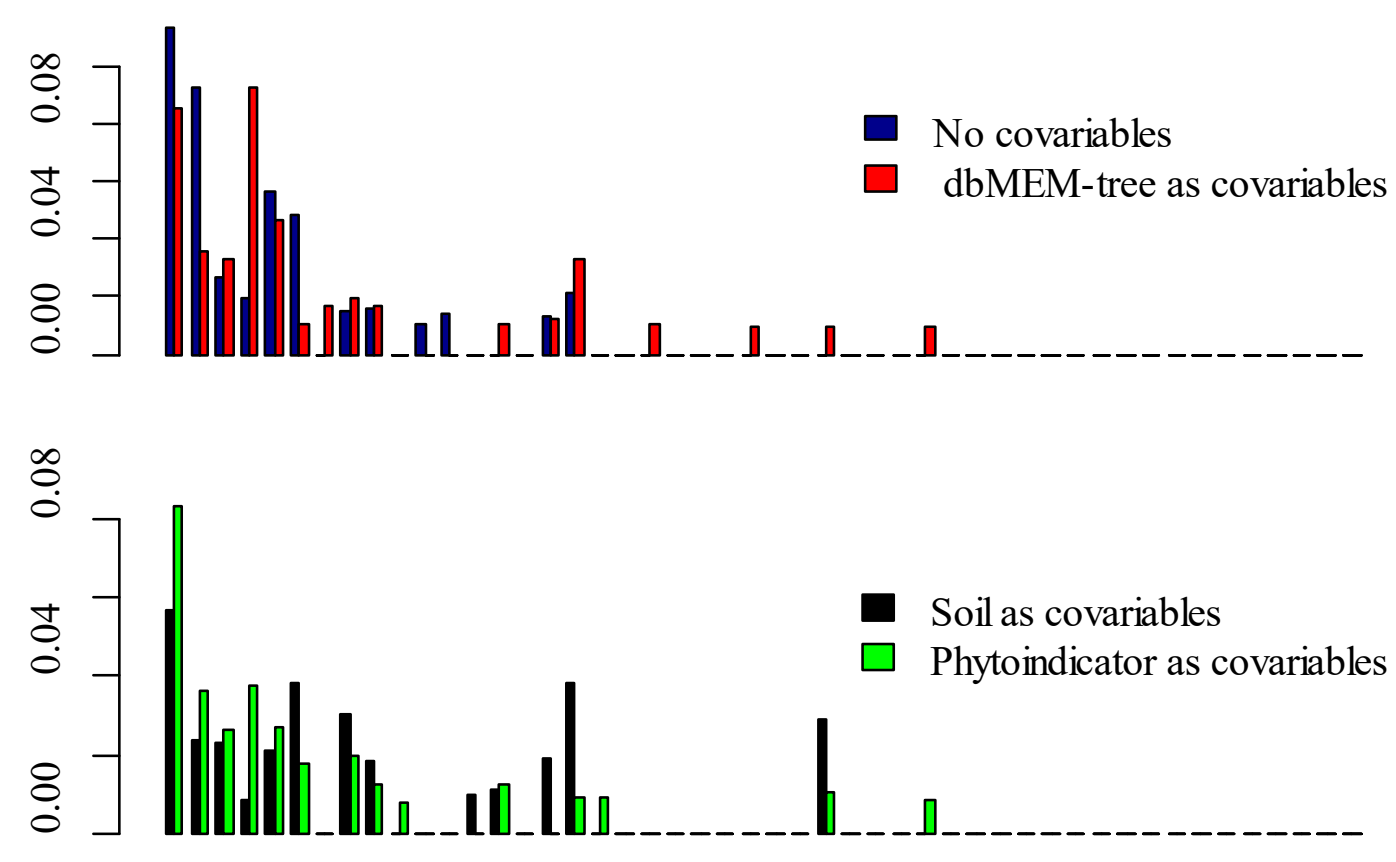
$\begin{array}{llllllllllllllllll}1 & 3 & 5 & 7 & 9 & 12 & 15 & 18 & 21 & 24 & 27 & 30 & 33 & 36 & 39 & 42 & 45 & 48\end{array}$

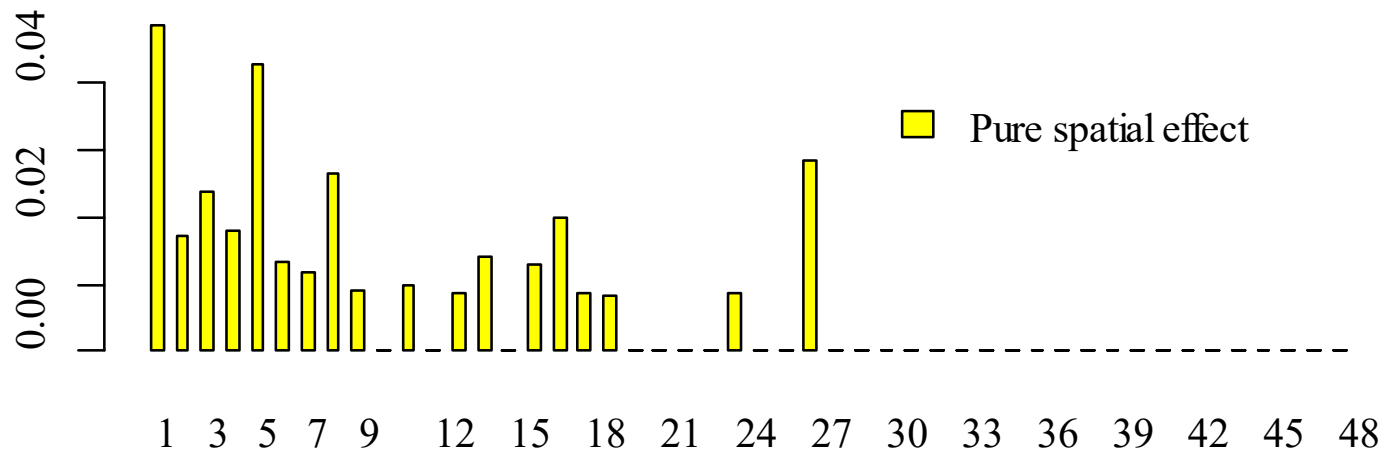

Figure 8. Scalograms illustrating the scaling of spatial structured variation in plant community data (No variables as covariables, blue bars) and residuals of the tree distance models (red bars), soil models (black bars), phytoindicator models (green bars) and pure spatial effect (yellow bars). The value of $R_{a d j}^{2}$ is the variation explained by individual dbMEM-spatial variables. The dbMEMs are ordered decreasingly according to the scale of spatial patterns they represent ( $x$-axis is the number of dbMEM; dbMEM 1 represents the broadest scale, dbMEM 48 the finest scale).

\section{Discussion}

The ground vegetation layer is the most diverse plant community in the forest ecosystems [40]. The niche assembly and dispersal assembly are discussed as the alternative explanations for community structure [41]. The niche assembly concept suggests that community structure is forced largely by environmental factors [42]. In our investigation we considered the effect on the herbaceous plant community of the forest ecosystem of such environmental factors, as the soil conditions and the impact of tree plants. Dispersal assembly postulates that community is structured by the ability of species to reach new habitats [41]. That is why spatial variables may be considered as the effective determinants of community composition [42]. In our work the spatial component of the variation was investigated as a factor of the plant community structure. 
Table 3. Variation in plant community structure explained by models with soil variables (statistically significant predictors are presented only)

\begin{tabular}{|c|c|c|c|c|c|c|c|c|}
\hline \multirow{3}{*}{ Variable } & \multirow{3}{*}{$\begin{array}{c}\text { Marginal } \\
\text { effect } \\
R^{2}{ }_{a d j}\end{array}$} & \multirow{3}{*}{$\begin{array}{c}p \text { - } \\
\text { value }\end{array}$} & \multicolumn{6}{|c|}{ Partial effect } \\
\hline & & & \multicolumn{2}{|c|}{ Spatial } & \multicolumn{2}{|c|}{ Phytoindicator } & \multicolumn{2}{|c|}{ Tree } \\
\hline & & & $R_{a d j}^{2}$ & $p$-value & $\boldsymbol{R}^{2}{ }_{a d j}$ & $p$-value & $\boldsymbol{R}_{a d j}^{2}$ & $p$-value \\
\hline \multicolumn{9}{|c|}{ Soil mechanical impedance at depth, MPa } \\
\hline $0-5 \mathrm{~cm}$ & 0.041 & 0.001 & 0.015 & 0.014 & 0.030 & 0.001 & 0.026 & 0.002 \\
\hline $30-35 \mathrm{~cm}$ & 0.070 & 0.001 & 0.020 & 0.009 & 0.061 & 0.001 & 0.060 & 0.001 \\
\hline $35-40 \mathrm{~cm}$ & 0.033 & 0.001 & 0.004 & 0.180 & 0.029 & 0.001 & 0.029 & 0.001 \\
\hline $45-50 \mathrm{~cm}$ & 0.016 & 0.009 & 0.001 & 0.310 & 0.008 & 0.031 & 0.019 & 0.001 \\
\hline $95-100 \mathrm{~cm}$ & 0.007 & 0.076 & 0.008 & 0.082 & 0.008 & 0.039 & 0.013 & 0.009 \\
\hline \multicolumn{9}{|c|}{ Other edaphic parameters } \\
\hline Density & 0.025 & 0.004 & 0.016 & 0.012 & 0.033 & 0.001 & -0.009 & 0.883 \\
\hline Moisture & 0.015 & 0.025 & 0.004 & 0.179 & 0.033 & 0.001 & 0.039 & 0.024 \\
\hline \multicolumn{9}{|c|}{ Aggregate fractions, $\mathrm{mm}$} \\
\hline $2-3$ & 0.013 & 0.023 & 0.008 & 0.067 & 0.027 & 0.001 & 0.006 & 0.206 \\
\hline $7-10$ & 0.005 & 0.130 & 0.003 & 0.241 & 0.024 & 0.003 & -0.009 & 0.873 \\
\hline
\end{tabular}

Note. Marginal effect represents variation explained by a given variable without the effect of other variables in the model. $P$-value accounting for autocorrelation was a significance of soil model with selected eigenvector-based spatial variables (dbMEMs) as covariables; Moisture - moisture of soil, \%; Density - soil density, $\mathrm{g} / \mathrm{cm}^{3}$

Herb-layer species are known to be sensitive and informative ecological indicators [43]. In our investigation the phytoindication estimations of the certain ecological factors were formally considered as a special source of the variation of plant community structure. The phytoindication estimates are a marker of the coordinated dynamics of plant community species, which is due to the similarity of plant responses to the effect of certain environmental factors [44]. It should be noted that we are far from the idea that a formal name of the indicated factors is fully consistent with the real environmental processes occurring within the investigated polygon. Such opinion is due to the fact that meaningful interpretation of phytoindication scales is based on the data obtained as a result of studying of the plant species responses to ecological factors at the scale level of the landscape or physical geographic zone [20]. Therefore, the interpretation of the phytoindication scales at the level of the some ecosystem should be treated with a certain degree of caution.

Herbaceous species are sensitive to the changes of environmental conditions [45]. The structure of plant community was revealed to correlate with physical properties of soil, but this correlation was due to the coordinated spatial trends of both vegetation and soil properties. Ground-layer vegetation in temporal forests is greatly affected by the overstorey composition and structure [46]. The pattern of soil properties under single forest trees is generally developed with radial symmetry to the tree, varying with distance from the tree trunk [47]. Trees were revealed to act as a significant and complicated structuring factor, which independently influences both on the vegetation community and on the physical properties of soil. The tree species composition can influence the dynamics of herbaceous species [48] by changing light availability [49] and enhancing the spatial heterogeneity of the soil [50].

The role of the trees to form the spatial patterns embraced mainly the broad-scale component, which allows to consider the influence of the trees canopy on the permeability to solar radiation as the main mechanism of such structuring effect. The limiting factors act as an environmental filter that influences both species richness and composition of the plant community. The competition for light and water is a main mechanism of the overstorey effect on the ground-layer vegetation [51]. This result is in agreement with hypothesis that environmental filtering is probably not very important at finer scales [8]. Neutral processes become weaker as a consequence of the greater heterogeneity of environmental conditions [52]. By scaling down, the number of individuals within a given grain or 
extent is reduced, and individual-based stochastic processes become more important [53]. As the size of the sampling plot decreased, the relative importance of environmental factors declined predominantly due to the reduction of environmental variability at finer scales [54].

Table 4. Significance of regression between subplot-based phytoindicator scale values and pure soil effects in species data (first significant CCA axe with soil predictors as explanatory variables and selected spatial and tree-distance variables as covariables, $F=1.67, p<0.001$ ), pure space (first five significant CCA axes with spatial predictors as explanatory variables and selected soil and treedistance variables as covariables, $F=3.17, p<0.001$ ), pure tree distance effect (first significant CCA with tree distance predictors as explanatory variables and selected soil and spatial variables as covariables)

\begin{tabular}{lcccccc}
\hline $\begin{array}{c}\text { Phytoindicator } \\
\text { scale* }\end{array}$ & $\begin{array}{c}\text { Soil effect } \\
\boldsymbol{R}^{2} \text { adj }\end{array}$ & $\boldsymbol{p}$-value & $\begin{array}{c}\text { Pure spatial } \\
\text { partial effect } \\
\boldsymbol{R}^{2} \text { adj }\end{array}$ & $\boldsymbol{p}$-value & $\begin{array}{c}\text { Tree partial } \\
\text { effect } \\
\boldsymbol{R}^{2} \text { adj }\end{array}$ & $\boldsymbol{p}$-value \\
\hline $\mathrm{Hd}$ & 0.04 & 0.04 & 0.02 & 0.26 & 0.01 & 0.17 \\
\hline $\mathrm{fH}$ & 0.03 & 0.07 & 0.19 & 0.00 & 0.00 & 0.40 \\
\hline $\mathrm{Rc}$ & 0.00 & 0.42 & 0.06 & 0.04 & 0.00 & 0.43 \\
\hline $\mathrm{Sl}$ & 0.04 & 0.06 & 0.08 & 0.02 & -0.01 & 0.77 \\
\hline $\mathrm{Ca}$ & 0.00 & 0.32 & 0.07 & 0.04 & -0.01 & 0.85 \\
\hline $\mathrm{Nt}$ & 0.03 & 0.08 & 0.13 & 0.00 & 0.02 & 0.09 \\
\hline $\mathrm{Ae}$ & -0.02 & 0.89 & -0.04 & 0.93 & -0.01 & 0.52 \\
\hline $\mathrm{Tm}$ & 0.04 & 0.04 & 0.09 & 0.02 & -0.01 & 0.83 \\
\hline $\mathrm{Om}$ & -0.01 & 0.69 & 0.28 & 0.00 & 0.00 & 0.31 \\
\hline $\mathrm{Kn}$ & 0.07 & 0.01 & 0.15 & 0.00 & -0.01 & 0.70 \\
\hline $\mathrm{Cr}$ & -0.01 & 0.52 & 0.18 & 0.00 & 0.00 & 0.24 \\
\hline $\mathrm{Lc}$ & 0.01 & 0.23 & 0.07 & 0.03 & -0.01 & 0.84 \\
\hline $\mathrm{Note}$ & & 0.03 &
\end{tabular}

Note: * $\mathrm{Hd}$ - soil water regime; $\mathrm{fH}$ - variability of damping; $\mathrm{Rc}$ - soil acidity; $\mathrm{Sl}$ - total salt regime; $\mathrm{Ca}$ - carbonate content in soil; $\mathrm{Nt}$ - nitrogen content in soil; Ae - soil aeration; $\mathrm{Tm}$ - thermal climate (thermoregime); Om - humidity; $\mathrm{Kn}$ - continentality of climate; $\mathrm{Cr}$ - cryo-climate; Lc - light

Community composition may be spatially structured independent of environment if dispersal limitation is a main assembly process [55]. Obtained data reveled that the pure spatial component was able to explain $11.0 \%$ of the plant community variation. Spatial distances may be considered as a surrogate for dispersal through space over time [56]. Spatial component of the plant community variation may be caused by the impact both of the unmeasured environmental variables with spatial structure [57] and of the effect of a neutral nature [58]. The pure spatial influence had complicated structure, which was confirmed by the high number of significant CCA-axes extracted after application of the spatial variables as predictors and their wide-scale range. Also, the pure spatial component was shown to be a statistically significant predicator of the phytoindication factors, revealing the important role of the non-measured factors in the formation of the spatial patterns of vegetation [59]. The use of space across different scales in the community analysis could be useful [60]. The pure spatial component covered the broad- and medium-scale range. As a mechanism of the occurrence of pure spatial component plant community variation one can assume the phenomena of species dispersal-limitation and vegetative growth, as well as competitive interaction between plant species [61]. The biotic interactions (e.g., competition) and historical processes, such as colonization and local extinctions are important drivers of the species richness and composition [62]. The herbaceous species actively compete for soil nutrients [63]. As scale becomes finer, dispersal or biotic processes such as interspecies interactions increase their importance [60].

Our results are in an agreement with statement that the soil properties largely influence the plant community [64]. The understory species composition of the poplar-willow forest was best explained by the soil mechanical impedance, litter depth, soil temperature and soil moisture, and soil aggregate 
structure [5]. Abiotic processes, are generally considered as environmental filters, which select those species that match the specific habitat requirements [65]. The soil mechanical impedance at different depths, soil bulk density and water content, and the content of the mesoaggregates had the considerable effect on the herbaceous community. This result is consistent with evidence that a root elongation stops in soil with a penetrometer resistance of 0.8 to $5.0 \mathrm{MPa}$ [66]. The critical value of the soil mechanical impedance for the growth of plant root systems is $3 \mathrm{MPa}$ [67]. In our investigation such value was observed from the depth of 55-60 cm and deeper. The coherent patterns of variation both the plant cover and the soil mechanical impedance at the depth of 35-50 cm, soil moisture and the content of aggregates 7-10 $\mathrm{mm}$ were caused by their common response to the general impact of the spatially structured process. Soil aggregate structure is critical to plant growth [68]. But the reverse is also true: vegetation affects soil structure at different scales and through a wide variety of mechanisms [69]. The scale of observation effects on the relative importance of specific environmental factors [70]. The influence of the environmental factors was revealed as progressively decreasing from broader to finer spatial scales [9]. The effect of the above-mentioned soil properties on vegetation community was independent from the phytoindication estimates of the environmental factors and from the influence of trees on the space organization of environmental conditions. The peculiarities of the organization of the flooded soil can be considered as a source of such spatial process which is depended on the intensity of sediments deposition during the flood. The complex and mosaic organization of the flood soil is due to the floodplain are among the most young and dynamic elements of the relief. They formed in the Holocene and continue to develop actively [23]. Floodplain ecosystems are complicated natural complexes that are characterized by significant spatial variability [71]. Soils in floodplain areas are affected by erosion processes and sedimentation phenomena, as well as transformation and translocation of the substance, which generally has the consequences of a constant impact that forms the veins and layers of sandy or clay deposits and of varying degrees of humus accumulation [72].

\section{Conclusion}

The pure spatial component is most important to explain the variation of the herb-layer community in a riparian mixed forest than the effect of soil and tree distance variables. The pure spatial influence had complicated structure. The important role of the non-measured factors in the formation of the spatial patterns of vegetation was revealed. The species dispersal-limitation and vegetative growth, as well as competitive interaction between plant species were suggested as a source of the pure spatial component of the herb-layer community variation. The soil mechanical impedance at different depths, soil bulk density and water content, and the content of the mesoaggregates had the considerable effect on the herbaceous community. Trees were revealed to act as a significant and complicated structuring factor, which independently influences both on the vegetation community and on the physical properties of soil.

\section{Conflict of Interest}

The authors declare that there is no conflict of interest between them.

\section{Acknowledgements}

The authors are grateful to the staff of the "Dniprovsko-Orilsky" Nature Reserve for their support and assistance with this research. We thank the two anonymous reviewers for helping us to improve earlier versions of this paper. 


\section{References}

[1] O.V. Zhukov, N.L. Gubanova, Dynamic stability of communities of amphibians in short-termfloodedforest ecosystems, Visnyk of Dnipropetrovsk University. Biology, ecology. 23 (2) (2015) 161-171. doi:10.15421/011523

[2] Y. I. Gritsan et al., The catena aspect of the landscape diversity of the «Dnipro-Orilsky» natural reserve, Journal of Geology, Geography and Geoecology. 28(3) (2019) 417-431. doi: $10.15421 / 111939$

[3] O.V. Zhukov, N.L. Gubanova, Diversity and dynamics of amphibians in floodplain ecosystems of the Samara river, Visnyk of Dnipropetrovsk University. Biology, ecology. 23(1) (2015) 6673. doi:10.15421/011510

[4] C. G. Jones, J. H. Lawton, M. Shachak, Organisms as ecosystem engineers, Oikos. 69 (1994) 373-386. DOI: $10.2307 / 3545850$

[5] O. Zhukov et al., The effect of soil on spatial variation of the herbaceous layer modulated by overstorey in an Eastern European poplar-willow forest, Ekológia (Bratislava). 38(3) (2019) 353-372. DOI:10.2478/eko-2019-0020

[6] A. Burns et al., Contribution of neutral processes to the assembly of gut microbial communities in the zebrafish over host development, The Multidisciplinary Journal of Microbial Ecology. 10 (2016) 655-664. doi:10.1038/ismej.2015.142

[7] K. Cottenie, Integrating environmental and spatial processes in ecological community dynamics, Ecology Letters. 8 (2005) 1175-1182. doi:10.1111/j.1461-0248.2005.00820.x

[8] M. Chudomelová et al., Contrasting patterns of fine-scale herb layer species composition in $\begin{array}{lllll}\text { temperate } & \text { forests, } & \text { Acta } & \text { Oecologica. }\end{array}$ https://doi.org/10.1016/j.actao.2017.02.003

[9] E. Laliberte et al., Assessing the scale-specific importance of niches and other spatial processes on beta diversity: a case study from a temperate forest, Oecologia. 159 (2009) 377-388. doi: $10.1007 / \mathrm{s} 00442-008-1214-8$

[10] A.V. Zhukov, G.A. Zadorozhnaya, Spatio-temporal dynamics of the penetration resistance of recultivated soils formed after open cast mining, Visnyk of Dnipropetrovsk University. Biology, ecology. 24(2) (2016) 324-331. DOI: 10.15421/011642

[11] O.V. Zhukov et al., Tree canopy affects soil macrofauna spatial patterns on broad- and mesoscale levels in an Eastern European poplar-willow forest in the floodplain of the River Dnipro, Folia Oecologica. 46(2) (2019) 123-136. doi: 10.2478/foecol-2019-0015

[12] J. G. Paluch, P. Gruba, Effect of local species composition on topsoil properties in mixed stands with silver fir (Abies alba Mill.), Forestry: An International Journal of Forest Research. 85(3) (2012) 413-426. https://doi.org/10.1093/forestry/cps040

[13] D. Binkley, C. Giardina, Why do Tree Species Affect Soils? The Warp and Woof of Tree-soil Interactions, Biogeochemistry. 42(1-2) 89-106. https://doi.org/10.1023/A:1005948126251

[14] L. Blank, Y. Carmel, Woody vegetation patch type determines herbaceous species richness and composition in Mediterranean ecosystem, Community Ecology. 13 (2012) 72-81. https://doi.org/10.1556/ComEc.13.2012.1.9

[15] T.J. Stohlgren, A.J. Owen, M. Lee, Monitoring shifts in plant diversity in response to climate change: a method for landscapes, Biodiversity and Conservation. 9(1) (2000) 65-86. https://doi.org/10.1023/A:1008995726486 
[16] A. V.Zhukov, Phytoindicator estimation of the multidimensional scaling of the plant community structure, Biological Bulletin of Bogdan Chmelnitskiy Melitopol State Pedagogical University. 1(1) (2015) 69-93. DOI: http://dx.doi.org/10.15421/2015005

[17] D.Oijen et al., Effects of tree species composition on within-forest distribution of understorey species, Applied Vegetation Science. 8(2) (2005) 155-166. doi:10.1111/j.1654109X.2005.tb00641.x

[18] P.M. Dixon, Nearest-neighbor contingency table analysis of spatial segregation for several species, Ecoscience. 9(2) (2002) 142-151. https://www.jstor.org/stable/42901478

[19] L.V. Borsukevish, V.A. Onishenko, Moist and occasionally flooded oak-elm forests, in: A.A. Kuzemko et al. (Eds.), National habitat catalogue of Ukraine, FOP Yu.Ia. Klymenko, Kyiv, 2018, pp. 262-263.

[20] Y. P. Didukh, The ecological scales for the species of Ukrainian flora and their use in synphytoindication, Phytosociocentre, Kyiv, 2011.

[21] O.V. Zhukov, Influence of usual and dual wheels on soil penetration resistance: the GISapproach, Biological Bulletin Of Bogdan Chmelnitskiy Melitopol State Pedagogical University. 3 (2015) 73-100. DOI: 10.7905/bbmspu.v5i3.988

[22] A.V. Zhukov et al., Geostatistical estimation of soil aggregate structure as a composite variable, Biological Bulletin. 3 (2015) 101-121. http://dx.doi.org/10.7905/bbmspu.v5i3.989

[23] V. M. Yakovenko, J.J. Dubinina, Y.O. Zhukova, Spatial heterogeneity of the physical properties of the soil in the floodplain of the small river, Agrology. 2(4) (2019) 219-228. doi: $10.32819 / 019031$

[24] Ch. F. Damgaard, K. M. Irvine, Using the beta distribution to analyse plant cover data, Journal of Ecology. 107 (2019) 2747-2759. https://doi.org/10.1111/1365-2745.13200

[25] R Core Team, R: A language and environment for statistical computing, R Foundation for Statistical Computing. Vienna, Austria, 2019. URL https://www.R-project.org/.

[26] A. M., Thieler, R. Fried, J. Rathjens, RobPer: An R Package to Calculate Periodograms for Light Curves Based on Robust Regression, Journal of Statistical Software. 69(9) (2016) 1-36. doi:10.18637/jss.v069.i09

[27] A. Canty, \& B. Ripley boot: Bootstrap R (S-Plus) Functions. R package version 1.3-20, 2017.

[28] C. J. F. Ter Braak, Canonical correspondence analysis: A new eigenvector technique for multivariate direct gradient analysis, Ecology. 67 (1986) 1167-1179. DOI: 10.2307/1938672

[29] F.G. Blanchet, P. Legendre, D. Borcard, Forward selection of explanatory variables, Ecology. 89(9) (2008) 2623-2632. https://doi.org/10.1890/07-0986.1

[30] D. Borcard, P. Legendre, All-scale spatial analysis of ecological data by means of principal coordinates of neighbour matrices, Ecological Modelling. 153 (2002) 51-68. https://doi.org/10.1016/S0304-3800(01)00501-4

[31] P. Legendre, L. Legendre, Numerical Ecology. Third English Edition. Elsevier Science, Amsterdam, NL., 2012.

[32] L.-W. Chang et al., Better environmental data may reverse conclusions about niche-and dispersal-based processes in community assembly, Ecology. 94 (2013) 2145-2151. https://doi.org/10.1890/12-2053.1

[33] O.V. Zhukov et al., Diversity and phytoindication ability of plant community, Ukrainian Journal of Ecology. 7(4) (2017) 81-99. DOI: http://dx.doi.org/10.15421/2017_90 
[34] J. Oksanen et al., Community Ecology Package. R package version 2.5-2, 2018. https://CRAN.R-project.org/package=vegan

[35] C.J.F. ter Braak, I.C. Prentice, A theory of gradient analysis, Advances in Ecological Research. 18 (1988) 271-317. https://doi.org/10.1016/S0065-2504(08)60183-X

[36] S. Dray et al., adespatial: Multivariate Multiscale Spatial Analysis. R package version 0.3-2, 2018. https://CRAN.R-project.org/package=adespatial

[37] M. De la Cruz, Metodos para analizar datos puntuales, in: F. T. Maestre, A. Escudero, A. Bonet (Eds.), Introduccion al Analisis Espacial de Datos en Ecologia y Ciencias Ambientales: Metodos y Aplicaciones, Asociacion Espanola de Ecologia Terrestre, Universidad Rey Juan Carlos y Caja de Ahorros del Mediterraneo, Madrid, 2008, pp. 76-127.

[38] A. Baddeley, R. Turner, Spatstat: an R package for analyzing spatial point patterns, Journal of Statistical Software. 12 (2005) 1-42. DOI: 10.18637/jss.v012.i06

[39] A.V. Smagin et al., Some criteria and estimation methods of soil ecological conditions regards to greenery of urban areas, Soil Sciences. 5 (2006) 603-615.

[40] F. S. Gilliam, The ecological significance of the herbaceous layer in temperate forest ecosystems, Bioscience. 57 (2007) 845-858. https://doi.org/10.1641/B571007

[41] T. Dallas, J. M. Drake, Relative importance of environmental, geographic, and spatial variables on zooplankton metacommunities, Ecosphere. 5(9) (2014) 104. http://dx.doi.org/10.1890/ES14-00071.1

[42] E. Weiher et al., Advances, challenges and a developing synthesis of ecological community assembly theory, Philosophical Transactions of the Royal Society B. 366 (2011) 2403-2413. https://doi.org/10.1098/rstb.2011.0056

[43] T. Standovár et al., Sensitivity of ground layer vegetation diversity descriptors in indicating forest naturalness, Community Ecology. 7(2) (2006) 199-209. https://doi.org/10.1556/ComEc.7.2006.2.7

[44] O.V. Zhukov, O. M. Kunah, Y.Y. Dubinina, Sensitivity and resistance of communities: evaluation on the example of the influence of edaphic, vegetation and spatial factors on soil macrofauna, Biosystems Diversity. 25(4) (2017) 328-341. doi:10.15421/011750

[45] G. von Oheimb, W. Härdtle, Selection harvest in temperate deciduous forest: impact on herb layer richness and composition, Biodiversity and Conservation. 18(2) (2009) 271-287. DOI: $10.1007 / \mathrm{s} 10531-008-9475-4$

[46] S. Barbier, F. Gosselin, P. Balandier, Influence of tree species on understory vegetation diversity and mechanisms involved - A critical review for temperate and boreal forests, Forest Ecology and Management. 254 (2008) 1-15. https://doi.org/10.1016/j.foreco.2007.09.038

[47] P. Zinke, The Pattern of Influence of Individual Forest Trees on Soil Properties, Ecology. 43(1) (1962) 130-133. https://doi.org/10.2307/1932049

[48] S. Bratton, Resource division in an understory herb community: responses to temporal and microtopographic gradients, The American Naturalist. 110(974) (1976) 679-693. www.jstor.org/stable/2459584.

[49] D. Breshears et al., Overstory-Imposed Heterogeneity in Solar Radiation and Soil Moisture in a Semiarid Woodland, Ecological Applications. 7(4) (1997) 1201-1215. doi:10.2307/2641208

[50] E. Andivia et al., Tree patch distribution drives spatial heterogeneity of soil traits in cork oak woodlands, Annals of Forest Science. 72 (2015) 549-559. https://doi.org/10.1007/s13595-015$0475-8$ 
[51] S. Burrascano, F. M. Sabatini, \& C. Blasi, Testing indicators of sustainable forest management on understorey composition and diversity in southern Italy through variation partitioning, Plant Ecology. 212 (2011) 829-841. https://doi.org/10.1007/s11258-010-9866-y

[52] F. C. Nettesheim et al., Environment is more relevant than spatial structure as a driver of regional variation in tropical tree community richness and composition, Plant Ecology \& Diversity. 11(1) (2018) 1755-1774. DOI: 10.1080/17550874.2018.1473520

[53] J. M. Chase, Spatial scale resolves the niche versus neutral theory debate, Journal of Vegetation Science. 25 (2014) 319-322. DOI: 10.1111/jvs.12159

[54] L.E. Frelich, J.L. Machado, P.B. Reich, Fine scale environmental variation and structure of understorey plant communities in two old growth pine forests, Journal of Ecology. 91 (2003) 283-293. https://doi.org/10.1046/j.1365-2745.2003.00765.x

[55] M. Aiba, H. Takafumi, T. Hiura, Interspecific differences in determinants of plant species distribution and the relationships with functional traits, Journal of Ecology. 100 (2012) 950957. doi:10.1111/j.1365-2745.2012.01959.x

[56] J. Karst, B. Gilbert, M.J. Lechowicz, Fern community assembly: the roles of chance and the environment at local and intermediate scales, Ecology. 86 (2005) 2473-2486. https://doi.org/10.1890/04-1420

[57] P. Legendre et al., Partitioning beta diversity in a subtropical broadleaved forest of China, Ecology. 90 (2009) 663-674. https://doi.org/10.1890/07-1880.1

[58] S. P. Hubbell, The unified neutral theory of biodiversity and biogeography. Princeton University Press, Princeton, New Jersey, USA, 2001.

[59] O.N. Kunah, Functional and spatial structure of the urbotechnozem mesopedobiont community, Visnyk of Dnipropetrovsk University. Biology, ecology. 24(2) (2016) 473-483. DOI https://doi.org/10.15421/011664

[60] A. Gazol, R. Ibanez, Plant species composition in a temperate forest: Multi-scale patterns and determinants, Acta $\quad$ Oecologica. $\quad 36 \quad$ (2010) 634-644. https://doi.org/10.1016/j.actao.2010.09.009

[61] H. Tuomisto, K. Ruokolainen, M. Yli-Halla, Dispersal, environment, and floristic variation of Western Amazonian forests, Science. 299 (2003) 241-244. DOI: 10.1126/science.1078037

[62] J. G. Pausas, M. P. Austin, Patterns of plant species richness in relation to different environments: An appraisal, Journal of Vegetation Science. 12 (2001) 153-166. https://doi.org/10.2307/3236601

[63] J. Lyon, W.E. Sharpe, Impacts of hay-scented fern on nutrition of northern red oak seedlings, Journal of Plant Nutrition. 26(3) (2003) 487-502. https://doi.org/10.1081/PLN-120017661

[64] O. M. Kunah et al., The temporal dynamics of readily available soil moisture for plants in the technosols of the Nikopol Manganese Ore Basin, Biosystems Diversity. 27(2) (2019) 156-162. doi:10.15421/011921

[65] Z. Lososová et al., Phylogenetic structure of plant species pools reflects habitat age on the geological time scale, Journal of Vegetation Science. 26 (2015) 1080-1089. doi:10.1111/jvs. 12308

[66] E.L. Greacen, D.A. Farrell, B. Cockroft, Soil resistance to metal probes and plant roots, Transactions of the 9th Congress of the International Society of Soil Science. 1 (1968) 769 779 .

[67] V.V. Medvedev, Soil penetration resistance, Gorodskaya Tipografiya, Kharkov, 2009. 
[68] Y. Canton al., Aggregate stability in range sandy loam soils Relationships with runoff and erosion, Catena. 77 (2009) 192-199. DOI: 10.1016/j.catena.2008.12.011

[69] D.A. Angers, J. Caron, Plant-induced Changes in Soil Structure: Processes and Feedbacks, Biogeochemistry. 42(1-2) (1998) 55-72. https://doi.org/10.1023/A:1005944025343

[70] A. Siefert al., Scale dependence of vegetation-environment relationships: a meta-analysis of multivariate data, Journal of Vegetation Science. 23 (2012) 942-951. https://doi.org/10.1111/j.1654-1103.2012.01401.x

[71] J. Rinklebe, U. Langer, Microbial diversity in three floodplain soils at the Elbe River (Germany), Soil Biology and Biochemistry. 38(8) (2006) 2144-2151. https://doi.org/10.1016/j.soilbio.2006.01.01

[72] K. Wälder, O. Wälder, J. Rinklebe, J. Menz, Estimation of soil properties with geostatistical methods in floodplains, Archives of Agronomy and Soil Science. 54(3) (2008) 275-295. 